УДК 546.284’31

\title{
ЭЛЕМЕНТНЫЙ СОСТАВ ОБРАЗЦОВ АМОРФНОГО КРЕМНЕЗЕМА БИОГЕННОГО ПРОИСХОЖДЕНИЯ
}

\author{
() Л.А. Земнухова ${ }^{1,2 *}$, Н.В. Полякова, Г.А. Федорищева ${ }^{I}$, Е.А. Цой \\ ${ }^{1}$ Институт химии Дальневосточного отделения РАН, пр. 100-летия \\ Владивостока, 159, Владивосток, 690022 (Россия), e-mail: laz@ich.dvo.ru \\ ${ }^{2}$ Дальневосточный фредеральный университет, ул. Суханова, 8, \\ Владивосток, 690050 (Россия)
}

\begin{abstract}
Приведены результаты исследования элементного состава образцов аморфного кремнезема, полученных из рисовой соломы, плодовых оболочек (шелухи) риса и овса, хвои лиственницы и хвощей, в сравнении с образцами, выделенными из минерального сырья, с использованием ряда физико-химических методов анализа (рентгенофазовый, ИКспектроскопический, весовой, термогравиметрический, рентгенофлуоресцентный с полным внешним отражением) с целью оценки качества перспективного возобновляемого растительного сырья.

Ключевые слова: аморфный диоксид кремния, солома риса, шелуха риса и овса, хвоя лиственницы, хвощи.
\end{abstract}

\section{Введение}

Соединение диоксид кремния (кремнезем), $\mathrm{SiO}_{2}$, характеризуется необычным полиморфизмом, кристаллические формы и свойства которого хорошо изучены [1], в отличие от некристаллических фаз, сведения о которых относятся в основном к описанию гидрогелей опалов, пористого или модифицированных кремнеземов [2, 3]. Аморфные формы кремнезема, способы их получения из разного кремнийсодержащего сырья, свойства, определяющие дальнейшее использование в практике, в том числе в медицинской, продолжают привлекать внимание исследователей $[4,5]$. Растительное сырье содержит и природные биологически активные вещества, процесс выделения которых в большинстве случаев выгоднее химического синтеза. Для создания комплексных технологий переработки недревесного растительного сырья, которое до сих пор не находит эффективного использования, необходимы полные сведения о его химическом составе.

Наиболее перспективным источником аморфного кремнезема являются прежде всего возобновляемые многотоннажные отходы производства риса - плодовые оболочки или шелуха [6-9], которые концентрируются на предприятиях при очистке зерна в виде отходов и содержат в среднем $15-20$ масс.\% $\mathrm{SiO}_{2}$.

Ранее нами изучены способы извлечения аморфного кремнезема из соломы и шелухи риса и овса $[7,10]$,

Земнухова Людмила Алексеевна - заведующая лабораторией, доктор химических наук, профессор, тел: (4232) 31-35-66, факс: (4232) 31-18-89, e-mail: laz@ich.dvo.ru

Полякова Наталья Владимировна - старший научный сотрудник, кандидат химических наук, тел.: (4232) 31-35-66, факс: (4232) 31-18-89, e-mail:polyakova@ich.dvo.ru Федорищева Галина Алексеевна - ведущий инженертехнолог, тел.: (4232) 31-35-66, факс: (4232) 31-18-89, e-mail: laz@ich.dvo.ru

Цой Елена Александровна - аспирант, тел.: (4232) 31-35-66, e-mail: tsoy_el@mail.ru сорбционные свойства по отношению к растворам, содержащим ионы железа (III), меди (II), кадмия (II), свинца (II) [11] и цефалоспориновые антибиотики [12], а также структурные особенности диоксида кремния биогенного происхождения $[13,14]$.

Цель данной работы - исследование элементного состава аморфного диоксида кремния, полученного из растительного и минерального сырья, позволяющего провести оценку качества продукта и определить направления его использования.

\footnotetext{
* Автор, с которым следует вести переписку.
} 


\section{Экспериментальная часть}

Объектом исследования стали образцы аморфного диоксида кремния (табл. 1), которые выделены из соломы (1-4) и шелухи $(5,6)$ риса (Oryza sativa L.), шелухи овса (Avene sativa L.) (7), хвои лиственницы даурской (Larix dahuruca Turcz) (8), хвоща зимующего (Equisetum hyemale Z.) (9), хвоща лесного (Еquisetum sylvacum Z.) (10). Для сравнения изучены также образцы диатомита (11) из природного месторождения (Австралия), силикагеля для тонкослойной хроматографии (продукт завода «Красный пролетарий», Россия) (12) и реактив «Кремниевая кислота» (ГОСТ 4214-78) (13).

Образцы кремнезема 1-5 и 7-10 получены из исходного сырья (которое предварительно промыто водой и высушено на воздухе до постоянной массы) по одной методике, соответствующей схеме $\mathrm{V}$ в [7]: навеску сырья обрабатывали 0,1 н раствором $\mathrm{HCl}$ при $90{ }^{\circ} \mathrm{C}$ в течение 1 ч, промывали водой, а затем подвергали двухстадийному обжигу при температуре 350 , а затем - $750{ }^{\circ} \mathrm{C}$. Образец 6 получен следующим способом: навеску рисовой шелухи обрабатывали 1 н раствором гидроксида натрия при $90{ }^{\circ} \mathrm{C}$ в течение 1 ч; раствор, содержащий силикат натрия, отделяли от остатка сырья (из которого можно затем получать целлюзные материалы [15]) и осаждали кремниевую кислоту с помощью концентрированной соляной кислоты при $\mathrm{pH}=6$. Образовавшийся осадок $\mathrm{SiO}_{2} \cdot \mathrm{nH}_{2} \mathrm{O}$ промывали водой до полного удаления ионов хлора и сушили при $60{ }^{\circ} \mathrm{C}$.

Содержание основного вещества $\mathrm{SiO}_{2}$ определяли весовым методом, количество оксидов натрия, калия, магния, кальция и алюминия - атомно-абсорбционным, как в [7]. Наличие воды устанавливали с помощью ИК-спектроскопии, ее содержание определяли термогравиметрическим методом, а состояние вещества устанавливали рентгенофазовым анализом (РФА). Эти результаты представлены в таблице 1.

Элементный состав вещества, начиная с серы и далее по Периодической таблице, устанавливали рентгенофлуоресцентным анализом с полным внешним отражением (РФА ПВО) на спектрометре TXRF$8030 \mathrm{C}$ (Германия, трубка с W анодом, энергия возбуждения 32 кэВ, время измерения - 500 сек.). Расчет содержания элементов проводили по методу внутреннего стандарта по программе OXFORD, входящей в состав программы обработки спектров данного спектрометра. В качестве внутреннего стандарта использовали раствор азотнокислого иттрия $\mathrm{Y}\left(\mathrm{NO}_{3}\right)_{3}$ в соотношении 100 мкг Ү на 1 г исследуемого вещества.

Таблица 1. Образцы диоксида кремния, источник получения и содержание макрокомпонентов

\begin{tabular}{|c|c|c|c|c|c|c|c|c|c|c|c|}
\hline \multirow{2}{*}{ Образец } & \multirow{2}{*}{ Источник * $\mathrm{SiO}_{2}$ (сорт) } & \multirow{2}{*}{$\begin{array}{r}\text { Выход } \\
\mathrm{SiO}_{2}, \% \\
\end{array}$} & \multicolumn{8}{|c|}{ Содержание, \% } & \multirow{2}{*}{$\begin{array}{l}\text { Состояние по } \\
\text { данным РФА }\end{array}$} \\
\hline & & & $\mathrm{SiO}_{2}$ & $\mathrm{Na}_{2} \mathrm{O}$ & $\mathrm{K}_{2} \mathrm{O}$ & $\mathrm{MgO}$ & $\mathrm{CaO}$ & $\mathrm{Al}_{2} \mathrm{O}_{3}$ & $\mathrm{~S}$ & $\mathrm{H}_{2} \mathrm{O}$ & \\
\hline 1 & $\begin{array}{l}\text { Солома риса (Долин- } \\
\text { ный) }\end{array}$ & 16,2 & 92,11 & 0,085 & 1,29 & 0,461 & 0,75 & 0,062 & 0,14 & $<0,1$ & аморфное \\
\hline 2 & Солома риса (Луговой) & 11,5 & 93,65 & 0,061 & 0,58 & 0,385 & 0,83 & 0,062 & 0,053 & $<0,1$ & аморфное \\
\hline 3 & $\begin{array}{l}\text { Солома риса (Приозёр- } \\
\text { ный 61) }\end{array}$ & 13,4 & 91,57 & 0,101 & 1,55 & 0,403 & 0,406 & 0,236 & 0,13 & $<0,1$ & аморфное \\
\hline 4 & Солома риса (Дарий-8) & 12,3 & 93,62 & 1,48 & 3,31 & 0,55 & 0,89 & $\mathrm{H} / \mathrm{O}$ & H/O & 1,08 & аморфное \\
\hline 5 & $\begin{array}{l}\text { Шелуха риса (Дальне- } \\
\text { восточный) }\end{array}$ & 15,0 & 99,46 & 0,02 & 0,156 & 0,07 & 0,15 & 0,017 & 0,064 & 0,5 & аморфное \\
\hline 6 & Шелуха риса & 3,3 & 97,68 & 0,804 & 0,012 & 0,023 & 0,065 & 0,15 & H/O & 1,4 & аморфное \\
\hline 7 & Шелуха ог & 3,2 & 94,3 & 0,03 & 0,41 & 0,98 & 1,90 & 0,03 & 0,34 & 0,5 & аморфное \\
\hline 8 & енницы & 4,3 & 83,66 & 0,19 & 1,88 & 1,01 & 5,48 & 0,43 & 1,68 & 1,7 & аморфное \\
\hline 9 & Хвощ зимующий & 10,2 & 89,62 & 0,07 & 1,95 & 0,38 & 2,28 & 0,38 & 0,024 & 0,6 & $\begin{array}{c}\text { аморфно- } \\
\text { кристал- } \\
\text { лическое } \\
\text { (кварц) }\end{array}$ \\
\hline 10 & Хвощ лесной & 10,2 & 91,24 & 0,08 & 1,61 & 0,585 & 1,11 & 0,57 & 0,22 & 0,6 & $\begin{array}{c}\text { аморфно- } \\
\text { кристал- } \\
\text { лическое } \\
\text { (кварц) }\end{array}$ \\
\hline 11 & Диатомит & & 67,03 & 0,80 & 0,12 & 0,42 & 0,53 & 11,0 & $\mathrm{H} / \mathrm{O}$ & 14,06 & аморфное \\
\hline 12 & Силикагель & & 91,5 & 0,0087 & 0,037 & 0,0056 & 0,73 & 0,11 & $\mathrm{H} / \mathrm{O}$ & 8,25 & аморфное \\
\hline 13 & Реактив $\mathrm{SiO}_{2} \cdot \mathrm{nH}_{2} \mathrm{O}$ & & 88,4 & 0,01 & $\mathrm{H} / \mathrm{O}$ & 0,0056 & 0,050 & 0,08 & $\mathrm{H} / \mathrm{O}$ & 11,5 & аморфное \\
\hline
\end{tabular}

* Образцы сырья, место и год сбора: солома риса - п. Тимирязевский Приморского края, 2010 (1-3) и 2002 (4), октябрь; шелуха риса - Приморский край, 2008 (5) и Вьетнам (южный), 2001 (6); шелуха овса - Алтайский край, 2005; хвоя лиственницы и хвощи - Приморский край, 2002, июнь. 
Подготовку образца для анализа проводили следующим способом. Навеску вещества массой 0,142 г помещали в тефлоновый автоклав, куда приливали раствор внутреннего стандарта, добавляли по 1,5 мл плавиковой $(\mathrm{HF})$ и соляной $(\mathrm{HCl})$ кислот, очищенных перегонкой в аппарате изотермической дистилляции для получения сверхчистых кислот DistillacidBSB-939-IR (Berghof, Германия). Исследуемый образец разлагали в микроволновой печи Ultra Clave (Milestone, Италия) при $210^{\circ} \mathrm{C}$ и давлении 60 атм в течение 2 ч. Полученный прозрачный раствор упаривали в стеклоуглеродной чашке до удаления НF и образования влажных солей, которые растворяли затем в бидистилляте (15,2 МОм ) и анализировали методом РФА ПВО. Результаты исследования даны в таблицах 1 и 2. На рисунке показан один из спектров РФА ПВО кремнезема (образец 3).

Таблица 2. Состав примесных элементов в образцах аморфного кремнезема, по данным РФА ПВО, мкг/г $\left(\mathrm{Y}_{\mathrm{Ref}}=100,0 \mathrm{мкг/ \Gamma )}\right.$

\begin{tabular}{c|c|c|c|c|c|c|c|c|c|c|c|c|c|c|c|c|c}
\hline $\begin{array}{c}\text { № образца } \\
\text { по таблице 1 }\end{array}$ & $\mathrm{Ti}$ & $\mathrm{Cr}$ & $\mathrm{Mn}$ & $\mathrm{Fe}$ & $\mathrm{Ni}$ & $\mathrm{Cu}$ & $\mathrm{Zn}$ & $\mathrm{As}$ & $\mathrm{Rb}$ & $\mathrm{Sr}$ & $\mathrm{Zr}$ & $\mathrm{Mo}$ & $\mathrm{Cd}$ & $\mathrm{Sn}$ & $\mathrm{Sb}$ & $\mathrm{Ba}$ & $\mathrm{Pb}$ \\
\hline 1 & 499 & 17 & 1712 & 1100 & 17 & 28 & 386 & $\mathrm{H} / \mathrm{o}$ & 6 & 38 & $\mathrm{H} / \mathrm{o}$ & 2 & $\mathrm{H} / \mathrm{o}$ & $\mathrm{H} / \mathrm{o}$ & $\mathrm{H} / \mathrm{o}$ & $\mathrm{H} / \mathrm{o}$ & 5 \\
2 & 275 & 22 & 627 & 711 & 12 & 14 & 169 & $\mathrm{H} / \mathrm{o}$ & 2 & 12 & 2 & 1 & $\mathrm{H} / \mathrm{o}$ & $\mathrm{H} / \mathrm{o}$ & 77 & 15 & 3 \\
3 & 397 & 25 & 1215 & 1418 & 14 & 20 & 269 & $\mathrm{H} / \mathrm{o}$ & 6 & 23 & 7 & $\mathrm{H} / \mathrm{o}$ & $\mathrm{H} / \mathrm{o}$ & $\mathrm{H} / \mathrm{o}$ & $\mathrm{H} / \mathrm{o}$ & 18 & $\mathrm{H} / \mathrm{o}$ \\
4 & 1551 & $\mathrm{H} / \mathrm{o}$ & 7379 & 2857 & 19 & 57 & 1021 & $\mathrm{H} / \mathrm{o}$ & 23 & 46 & 41 & 13 & $\mathrm{H} / \mathrm{o}$ & $\mathrm{H} / \mathrm{o}$ & 37 & $\mathrm{H} / \mathrm{o}$ & 49 \\
5 & 493 & $\mathrm{H} / \mathrm{o}$ & 180 & 917 & $\mathrm{H} / \mathrm{o}$ & 9 & 38 & $\mathrm{H} / \mathrm{o}$ & 5 & 10 & 6 & 5 & $\mathrm{H} / \mathrm{o}$ & $\mathrm{H} / \mathrm{o}$ & 7 & $\mathrm{H} / \mathrm{o}$ & 14 \\
6 & 93 & 2 & 8 & 245 & 13 & 2 & 28 & $\mathrm{H} / \mathrm{o}$ & $\mathrm{H} / \mathrm{o}$ & 6 & 17 & $\mathrm{H} / \mathrm{o}$ & $\mathrm{H} / \mathrm{o}$ & 3 & 61 & 4 & 6 \\
7 & 630 & $\mathrm{H} / \mathrm{o}$ & 238 & 1314 & 14 & 58 & 473 & $\mathrm{H} / \mathrm{o}$ & 13 & 101 & 39 & 13 & $\mathrm{H} / \mathrm{o}$ & $\mathrm{H} / \mathrm{o}$ & 119 & 16 & 26 \\
8 & 2721 & $\mathrm{H} / \mathrm{o}$ & 2511 & 5877 & 36 & 351 & 324 & 26 & 32 & 588 & 38 & 9 & $\mathrm{H} / \mathrm{o}$ & $\mathrm{H} / \mathrm{o}$ & 60 & 205 & 34 \\
9 & 574 & $\mathrm{H} / \mathrm{o}$ & 93 & 1519 & 8 & 32 & 164 & $\mathrm{H} / \mathrm{o}$ & 17 & 137 & 11 & $\mathrm{H} / \mathrm{o}$ & $\mathrm{H} / \mathrm{o}$ & $\mathrm{H} / \mathrm{o}$ & 10 & 32 & 23 \\
10 & 768 & $\mathrm{H} / \mathrm{o}$ & 408 & 1994 & 7 & 274 & 161 & $\mathrm{H} / \mathrm{o}$ & 30 & 136 & 17 & 5 & 16 & $\mathrm{H} / \mathrm{o}$ & 37 & 57 & 39 \\
11 & 3170 & 38 & 50 & 18588 & 12 & 20 & 55 & 5 & 16 & 73 & 106 & 2 & $\mathrm{H} / \mathrm{o}$ & $\mathrm{H} / \mathrm{o}$ & $\mathrm{H} / \mathrm{o}$ & $\mathrm{H} / \mathrm{o}$ & 14 \\
12 & 1954 & H/o & $\mathrm{H} / \mathrm{o}$ & 1863 & $\mathrm{H} / \mathrm{o}$ & 35 & 96 & $\mathrm{H} / \mathrm{o}$ & $\mathrm{H} / \mathrm{o}$ & 39 & 330 & $\mathrm{H} / \mathrm{o}$ & $\mathrm{H} / \mathrm{o}$ & $\mathrm{H} / \mathrm{o}$ & $\mathrm{H} / \mathrm{o}$ & 62 & 18 \\
13 & 1472 & H/o & H/o & 279 & $\mathrm{H} / \mathrm{o}$ & 10 & 19 & $\mathrm{H} / \mathrm{o}$ & $\mathrm{H} / \mathrm{o}$ & 6 & 22 & $\mathrm{H} / \mathrm{o}$ & $\mathrm{H} / \mathrm{o}$ & $\mathrm{H} / \mathrm{o}$ & $\mathrm{H} / \mathrm{o}$ & $\mathrm{H} / \mathrm{o}$ & $\mathrm{H} / \mathrm{o}$ \\
\hline
\end{tabular}

Рентгенофлуоресцентный спектр образца 3 по таблице 1 (* - внутренний стандарт)

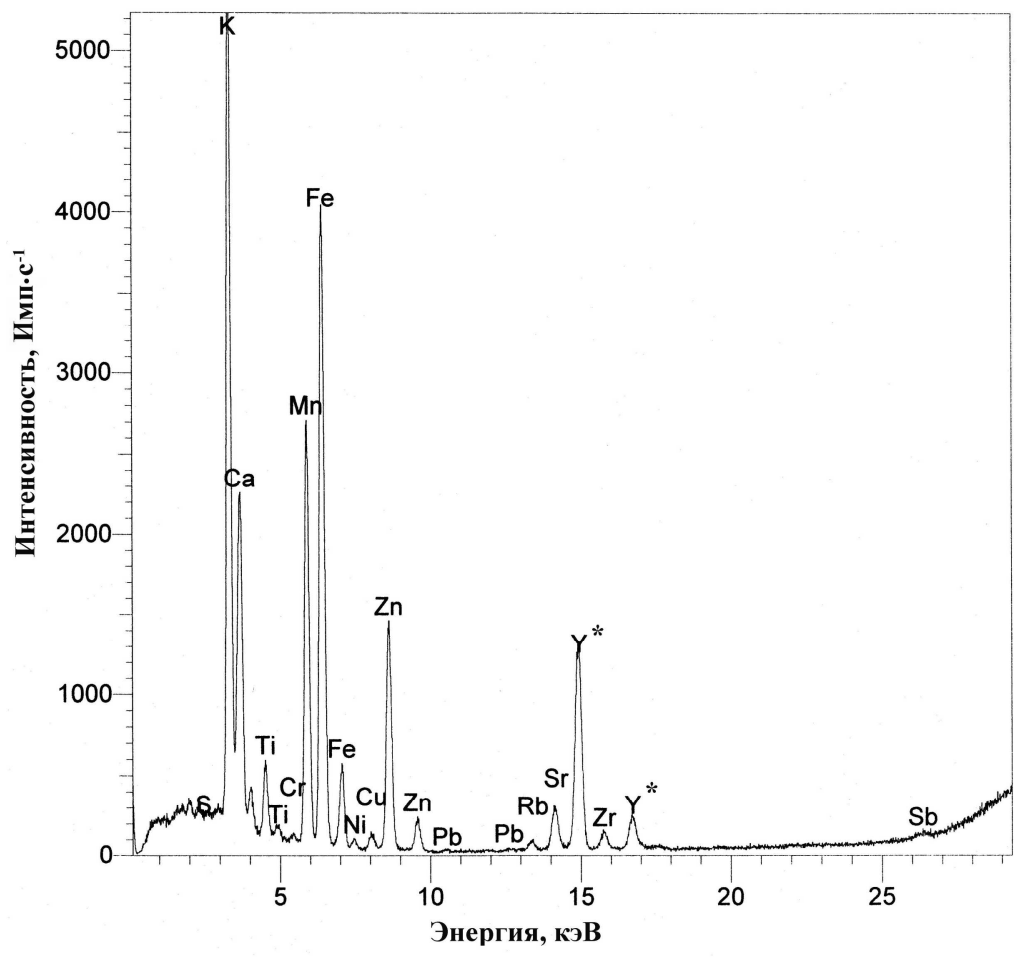

\section{Обсуждение результатов}

Результаты проведенных исследований показывают, что при окислительном обжиге растительного сырья, предварительно обработанного минеральной кислотой (образцы 1-5 и 7-10, табл. 1), образуется продукт, в котором содержание диоксида кремния составляет от 83 до 99\% в зависимости от растения. 
Наиболее чистым является кремнезем, выделенный из шелухи риса (5), как и в работе [7]. Все образцы кремнезема, кроме 9 и 10, имеют одинаковые рентгенограммы, указывающие на их аморфное состояние. Кремнезем, выделенный из хвощей (9 и 10), находится в двух формах - аморфной и кристаллической, последняя соответствует, по данным РФА, кварцу.

Выход кремнезема зависит от растения и способа извлечения (табл. 1). Так, содержание диоксида кремния в соломе риса разных сортов Приморской селекции колеблется в диапазоне 11-16\%, шелухе риса - $15 \%$. В шелухе овса (как и в [10]) и хвое лиственницы количество кремнезема небольшое - 3-4\%.

Следует отметить, что в образцах кремнезема, полученных из растений термическим обжигом (1-5 и 7-10) или осаждением (6) сорбированной воды значительно меньше $(<0,1-1,7 \%)$ в отличие от образцов минерального происхождения (11-13, табл. 1), что связано, видимо, с их разной характеристикой поверхности, как показано в [13].

Рентгенофлуоресцентный анализ с полным внешним отражением (РФА ПВО), использованный в данной работе и требующий небольшую навеску пробы (до 100 мг), относится к энергодисперсионному методу анализа и основан на регистрации характеристического излучения атомов элементов, возбужденных потоком $\gamma$-излучения анода рентгеновской трубки под малым углом, что повышает чувствительность метода (до $10^{-10} \%$ для некоторых элементов). Идентификацию выполняют по К и L сериям, энергии которых являются индивидуальными для каждого элемента. В случае отнесения элемента по К серии (от серы до бария) используют наиболее интенсивную К $\alpha$ линию спектра; если же элементы определяют по L серии (от лантана до урана), то во внимание берут две линии с близкими интенсивностями L $\alpha$ и L $\beta$.

На рисунке представлен спектр образца 3, в котором наблюдаются сигналы элементов, присутствующие в данном веществе. Самая интенсивная линия в спектре отнесена нами к Ка (3,7 кэВ) линии калия. Кроме того, по К $\alpha$ серии были идентифицированы следующие элементы: сера (2,3 кэВ), кальций (3,7 кэВ), титан (4,5 кэВ), хром (5,4 кэВ), марганец (5,9 кэВ), железо (6,4 кэВ), никель (7,5 кэВ), медь (8,.0 кэВ), цинк (8,6 кэВ), рубидий (13,4 кэВ), стронций (14,1 кэВ), цирконий (15,7 кэB), сурьма (26,3 кэB), а по L $\alpha, \beta$ серии - свинец (10,5 кэB L $\alpha, 1, .6$ кэB L $\beta)$. Результаты расчета концентраций, проведенные с помощью программного обеспечения спектрометра по методу внутреннего стандарта, приведены в таблице 1 (содержание оксидов калия и кальция, а также серы) и в таблице 2 (остальные элементы; количество сурьмы и свинца - на уровне фона).

Проведенный анализ образцов 1-13 позволил получить информацию о наличии и содержании 22 макро- и микроэлементов в диоксиде кремния в зависимости от исходного сырья. Ни в одном образце не обнаружены бром, ртуть и кобальт, небольшие количества которых были зафиксированы авторами [16] в золе хвоща полевого. Кадмий найден только в одном образце кремнезема (10), полученном из хвоща лесного, а мышьяк - в двух (8 и 11). Разный уровень концентрации отдельных микроэлементов в исследуемых образцах кремнезема из растений связан, видимо, прежде всего с природой растения. Например, кремнезем из хвои лиственницы (8) содержит больше титана, марганца, железа, меди, стронция, бария, чем образцы диоксида кремния из других растений $(1-5,7,9)$. В то же время разные части одного вида растения аккумулируют разные количества, например, хрома, марганца, меди или цинка. Так, в образцах кремнезема из разных сортов соломы риса (1-4) этих элементов содержится значительно больше, чем в образце из шелухи риса (5).

\section{Заключение}

Изучен элементный состав образцов аморфного диоксида кремния, полученного из кремнефильных растений: соломы риса, шелухи риса и овса, хвои лиственницы, хвоща зимующего и лесного, позволяющий провести оценку качества как потенциальных сырьевых материалов, так и конечных продуктов.

\section{Список литературь}

1. Химическая энциклопедия : в 5 т. / ред. И.Л. Кнунянц, Н.С. Зефиров. М., 1988-1999. 3360 с.

2. Айлер Р.К. Химия кремнезема. М., 1982. 1128 с.

3. Воронков М.Г., Кузнецов И.Г. Кремний в живой природе. Новосибирск, 1984. 286 с.

4. Урусов В.С., Шванская Л.В., Бычков А.Ю., Мохов А.В., Лабутова Е.А. Микроструктуры отложений кремнезема из термальных источников Камчатки // Доклады АН. 2008. Т. 418, №2. С. 262-266.

5. Медицинская химия и клиническое применение диоксида кремния / под ред. А.А. Чуйко. Киев, 2003. 416 с. 
6. Захаров А.И., Беляков А.В., Цвигунов А.Н. Формы выделения соединений кремния в рисовой шелухе // Стекло и керамика. 1993. №9-10. С. 37-41.

7. Земнухова Л.А., Федорищева Г.А., Егоров А.Г., Сергиенко В.И. Исследование условий получения, состава примесей и свойств аморфного диоксида кремния из отходов производства риса // Журнал прикладной химии. 2005. 78, вып. 2. C. 324-328.

8. Goncalves M.R.F., Bergman C.P. Thermal insulators made with rice husk ashes: production and correlation between properties and microstructure // Constr. Build. Mater. 2007. Vol. 21. Pp. 2059-2065.

9. Azadi M., Bahrololoom M.E., Heidari F. Enhancing the mechanical properties of an epoxy coating with rice husk ash, a green product // J. Coat. Technol. Res. 2011. Vol. 8. N1. Pp. 117-123.

10. Земнухова Л.А., Будаева В.В., Федорищева Г.А., Кайдалова Т.А., Куриленко Л.Н., Шкорина Е.Д., Ильясов С.Г. Неорганические компоненты соломы и шелухи овса // Химия растительного сырья. 2009. №1. С. 147-152.

11. Шевелева И.В., Холомейдик А.Н., Войт А.В., Земнухова Л.А. Сорбенты на основе рисовой шелухи для удаления ионов $\mathrm{Fe}(\mathrm{III}), \mathrm{Cu}(\mathrm{II}), \mathrm{Cd}$ (II), $\mathrm{Pb}$ (II) из растворов // Химия растительного сырья. 2009. №4. С. 171-176.

12. Соколова Л.И., Чучалина И.В., Земнухова Л.А. Концентрирование цефалоспориновых антибиотиков на модифицированных кремнеземах // Аналитика России : матер. II Всерос. конф. с международным участием. Краснодар, 2007. С. 238. (Электронный научный журнал «Исследовано в России» http://zhurnal.ape.relam.ru/articles/2006/196.pdf)

13. Земнухова Л.А., Бабушкина Т.А., Климова Т.П., Холомейдик А.Н. Пористая структура образцов аморфного кремнезема разного происхождения по данным ЯМР ${ }^{1} \mathrm{H} / /$ Журнал прикладной химии. 2010. Т. 83, вып. 2. С. $203-206$.

14. Земнухова Л.А., Николенко Ю.М. Исследование рисовой шелухи и продуктов ее переработки методом рентгеновской фотоэлектронной спектроскопии // Журнал общей химии. 2011. Т. 81. №4. С. 602-608.

15. Вураско А.В., Дрикер Б.Н., Земнухова Л.А., Галимова А.Р. Ресурсосберегающая технология получения целлюлозы при комплексной переработке соломы риса // Химия растительного сырья. 2007. №2. С. 21-25.

16. Коломиец Н.Э., Туева И.А., Мальцева О.А., Дмитрук С.Е.. Калинкина Г.И. Оценка перспективности некоторых видов лекарственного растительного сырья с точки зрения их экологической чистоты // Химия растительного сырья. 2004. №4. С. 25-28.

Поступило в редакиию 2 ноября 2011 2.

Zemnukhova L.A. ${ }^{1,2^{*}}$, Polyakova N.V. ${ }^{l}$, Fedorishcheva G.A. ${ }^{l}$, Tsoy E.A. ${ }^{2}$ ELEMENTARY COMPOSITION OF AMORPHOUS SILICA SAMPLES OF VARIOUS ORIGIN

${ }^{1}$ Institute of Chemistry, Far Eastern Branch of Russian Academy of Sciences, pr. 100-letiia Vladivostoka, 159,

Vladivostok, 690022 (Russia),e-mail:laz@ich.dvo.ru

${ }^{2}$ The Far Eastern Federal University, Suhanova St., 8, Vladivostok, 690950 (Russia)

The data on the elementary composition of the amorphous silica samples obtained from rice straw, rice and oats fruit shells (husk, hull), larch-tree needles, and horse-tail lichens are presented as compared to the samples prepared from mineral raw material using some methods of physico-chemical analysis (the X-ray diffraction, IR spectroscopy, weight method, thermogravimetry, X-ray fluorescence with total external reflection) for qualitative estimation of the perspective renewable vegetable raw material.

Keywords: amorphous silicon dioxide, rice straw, oats and rice hull, larch-tree needles, horse-tail lichens.

\section{References}

1. Khimicheskaia entsiklopediia: 5 t. / red. I.L. Knuniants, N.S. Zefirov [Chemical Encyclopedia. In 5 vol. Ed. I.L. Knunyants, N.S. Zefirov]. Moscow, 1988-1999, 3360 p. (in Russ.).

2. Ailer R.K. Khimiia kremnezema. [Chemistry of silica]. Moscow, 1982, 1128 p. (in Russ.).

3. Voronkov M.G., Kuznetsov I.G. Kremnii v zhivoi prirode. [Silicon in nature]. Novosibirsk, 1984, 286 p. (in Russ.).

4. Urusov V.S., Shvanskaia L.V., Bychkov A.Iu., Mokhov A.V., Labutova E.A. Doklady RAN, 2008, vol. 418, no. 2, pp. 262-266. (in Russ.).

5. Meditsinskaia khimiia i klinicheskoe primenenie dioksida kremniia. Ed. A.A. Chuiko. [Medicinal chemistry and clinical application of silicon dioxide. Ed. A.A. Chuiko.]. Kiev, 2003, 416 p. (in Russ.).

\footnotetext{
* Corresponding author.
} 
6. Zakharov A.I., Beliakov A.V., Tsvigunov A.N. Steklo i keramika, 1993, no. 9-10, pp. 37-41. (in Russ.).

7. Zemnukhova L.A., Fedorishcheva G.A., Egorov A.G., Sergienko V.I. Zhurnal prikladnoi khimii,. 2005, vol. 78, no. 2, pp. 324-328. (in Russ.).

8. Goncalves M.R.F., Bergman C.P. Constr. Build. Mater., 2007, vol. 21, pp. 2059-2065.

9. Azadi M., Bahrololoom M.E., Heidari F. J. Coat. Technol. Res., 2011, vol. 8, no. 1, pp. 117-123.

10. Zemnukhova L.A., Budaeva V.V., Fedorishcheva G.A., Kaidalova T.A., Kurilenko L.N., Shkorina E.D., Il'iasov S.G. Khimiia rastitel'nogo syr'ia, 2009, no. 1, pp. 147-152. (in Russ.).

11. Sheveleva I.V., Kholomeidik A.N., Voit A.V., Zemnukhova L.A. Khimiia rastitel'nogo syr'ia, 2009, no. 4, pp. $171-176$. (in Russ.).

12. Sokolova L.I., Chuchalina I.V., Zemnukhova L.A. Analitika Rossii: mater. II vseros. konf. s mezhdunarodnym uchastiem. [Russian analyst: Materials II All-Russian Conference with international participation.]. Krasnodar, 2007, p. 238. (Electronic scientific journal «Investigated in Russia» http://zhurnal.ape.relam.ru/articles/2006/196.pdf). (in Russ.).

13. Zemnukhova L.A., Babushkina T.A., Klimova T.P., Kholomeidik A.N. Zhurnal prikladnoi khimii, 2010, vol. 83, no. 2, pp. 203-206. (in Russ.).

14. Zemnukhova L.A., Nikolenko Iu.M. Zhurnal obshchei khimii, 2011, vol. 81, no. 4, pp. 602-608. (in Russ.).

15. Vurasko A.V., Driker B.N., Zemnukhova L.A., Galimova A.R. Khimiia rastitel'nogo syr'ia, 2007, no. 2, pp. 21-25. (in Russ.).

16. Kolomiets N.E., Tueva I.A., Mal'tseva O.A., Dmitruk S.E.. Kalinkina G.I. Khimiia rastitel'nogo syr'ia, 2004, no. 4, pp. 25-28. (in Russ.). 